\title{
Synaptic Kainate Receptors in CA1 Interneurons Gate the Threshold of Theta-Frequency-Induced Long-Term Potentiation
}

\author{
Vernon R.J. Clarke, ${ }^{1,4}$ Graham L. Collingridge, ${ }^{2,5}$ Sari E. Lauri, ${ }^{1,3}$ and Tomi Taira ${ }^{1,4}$ \\ ${ }^{1}$ Neuroscience Center, University of Helsinki, 00014 Helsinki, Finland, ${ }^{2}$ School of Physiology and Pharmacology, Medical Research Council Centre for \\ Synaptic Plasticity, University of Bristol, Bristol BS8 1TD, United Kingdom, ${ }^{3}$ Department of Biosciences and ${ }^{4}$ Department of Veterinary Biosciences, \\ University of Helsinki, 00014 Helsinki, Finland, and ${ }^{5}$ Department of Brain and Cognitive Sciences, College of Natural Sciences, Seoul National University, \\ Seoul 151-746, Korea
}

Theta oscillations $(4-12 \mathrm{~Hz})$ in neuronal networks are known to predispose the synapses involved to plastic changes and may underlie their association with learning behaviors. The lowered threshold for synaptic plasticity during theta oscillations is thought to be due to decreased GABAergic inhibition. Interneuronal kainate receptors (KARs) regulate GABAergic transmission and are implicated in theta activity; however, the physiological significance of this regulation is unknown. In rat hippocampus, we show that during theta activity, there is excitatory postsynaptic drive to CA1 interneurons mediated by KARs. This promotes feedforward inhibition of pyramidal neurons, raising the threshold for induction of theta-burst long-term potentiation. These results identify a novel mechanism whereby the activation of postsynaptic KARs in CA1 interneurons gate changes in synaptic efficacy to a physiologically relevant patterned stimulation.

\section{Introduction}

Interneurons are essential for correct spike timing and synchronization of local oscillatory activity in cortical circuits, including theta rhythms $(4-12 \mathrm{~Hz})$, gamma waves $(25-100 \mathrm{~Hz})$, and sharpwave ripples (100-200 Hz) (Somogyi and Klausberger, 2005; Mann and Paulsen, 2007). In addition, dynamic changes in excitatory input to interneurons affect feedforward GABAergic transmission onto principal neurons during patterned activity. Thus, interneurons play a critical role in the activation of $\mathrm{N}$-methyl-D-aspartate receptors (NMDARs) and the induction of long-term potentiation (LTP) in response to various protocols, including high-frequency and primed-burst/theta-burst stimulation (TBS) (Bliss and Collingridge, 1993). The latter mimic characteristic natural-type firing patterns of hippocampal pyramidal neurons in vivo, typically comprising short highfrequency bursts $[2-7$ action potentials (APs) at $\sim 100 \mathrm{~Hz}]$ at lower intraburst frequencies in the theta range $(4-10 \mathrm{~Hz}$ ) (Otto et al., 1991; O'Keefe and Recce, 1993). Oscillatory activity at theta frequencies, common in rat hippocampus, is particularly prominent during rapid-eye-movement sleep, voluntary movement (Vanderwolf, 1969), and exploratory behavior (O'Keefe and

\footnotetext{
Received May 14, 2012; revised Sept. 16, 2012; accepted 0ct. 18, 2012.

Author contributions: V.R.J.C., G.L.C., and T.T. designed research; V.R.J.C. performed research; V.R.J.C. analyzed data; V.R.J.C., G.L.C., S.E.L., and T.T. wrote the paper.

This work was supported by the Academy of Finland (S.E.L. and T.T.), the Sigrid Juselius Foundation (V.R.J.C., S.E.L., and T.T.) and the Medical Research Council of the United Kingdom (V.R.J.C. and G.L.C.).

The authors declare no competing financial interests.

Correspondence should be addressed to Vernon Clarke, Neuroscience Center, Viikinkaari 1 (P.0. Box 65), University of Helsinki, 00014 Helsinki, Finland. E-mail: vernon.clarke@helsinki.fi.

DOI:10.1523/JNEUROSCI.2327-12.2012

Copyright $\odot 2012$ the authors $\quad 0270-6474 / 12 / 3218215-12 \$ 15.00 / 0$
}

Recce, 1993). Such subthreshold rhythms enhance the induction of hippocampal NMDAR-dependent LTP when brief tetanic input occurs in phase with the depolarizing peak of endogenous oscillations in anesthetized (Pavlides et al., 1988) and awake behaving rats (Hyman et al., 2003) as well as during pharmacologically induced theta oscillations in vitro (Huerta and Lisman, 1993). This may explain the proposed significance of underlying theta rhythms during learning and memory (Buzsáki, 2005). Thus, TBS represents a natural-type paradigm optimally tuned to induce NMDAR-dependent synaptic plasticity.

That theta frequencies are optimal for LTP induction in vitro (Larson et al., 1986; Diamond et al., 1988) is due, in part, to presynaptic $\mathrm{GABA}_{\mathrm{B}}$ autoreceptors and consequent decrease in GABA release during primed (Davies et al., 1991) and theta-burst stimulation (Stäubli et al., 1999). Kainate receptors (KARs) regulate interneuronal activity in area CA1, providing postsynaptically mediated excitatory drive (Cossart et al., 1998, 2002; Frerking et al., 1998; Goldin et al., 2007; Wondolowski and Frerking, 2009). In addition, presynaptic KARs facilitate excitatory input onto a subset of interneurons (Sun et al., 2005; Sun and Dobrunz, 2006) and modulate GABA release onto CA1 pyramidal neurons (Clarke et al., 1997; RodríguezMoreno et al., 1997) in a heterosynaptic manner (Min et al., 1999). Modification of interneuronal excitability and/or output may underlie the observed reduction in theta frequency of hippocampal oscillations following KAR antagonism in vivo (Huxter et al., 2007). A prescient physiologically relevant question is whether interneuronal KARs play modulatory roles during patterned activity, such as TBS, and does this, in turn, have any effect on the induction of synaptic plasticity.

We show that during TBS, there is a GluK1 subunit-containing KAR-mediated component of glutamatergic synaptic transmission at 
A
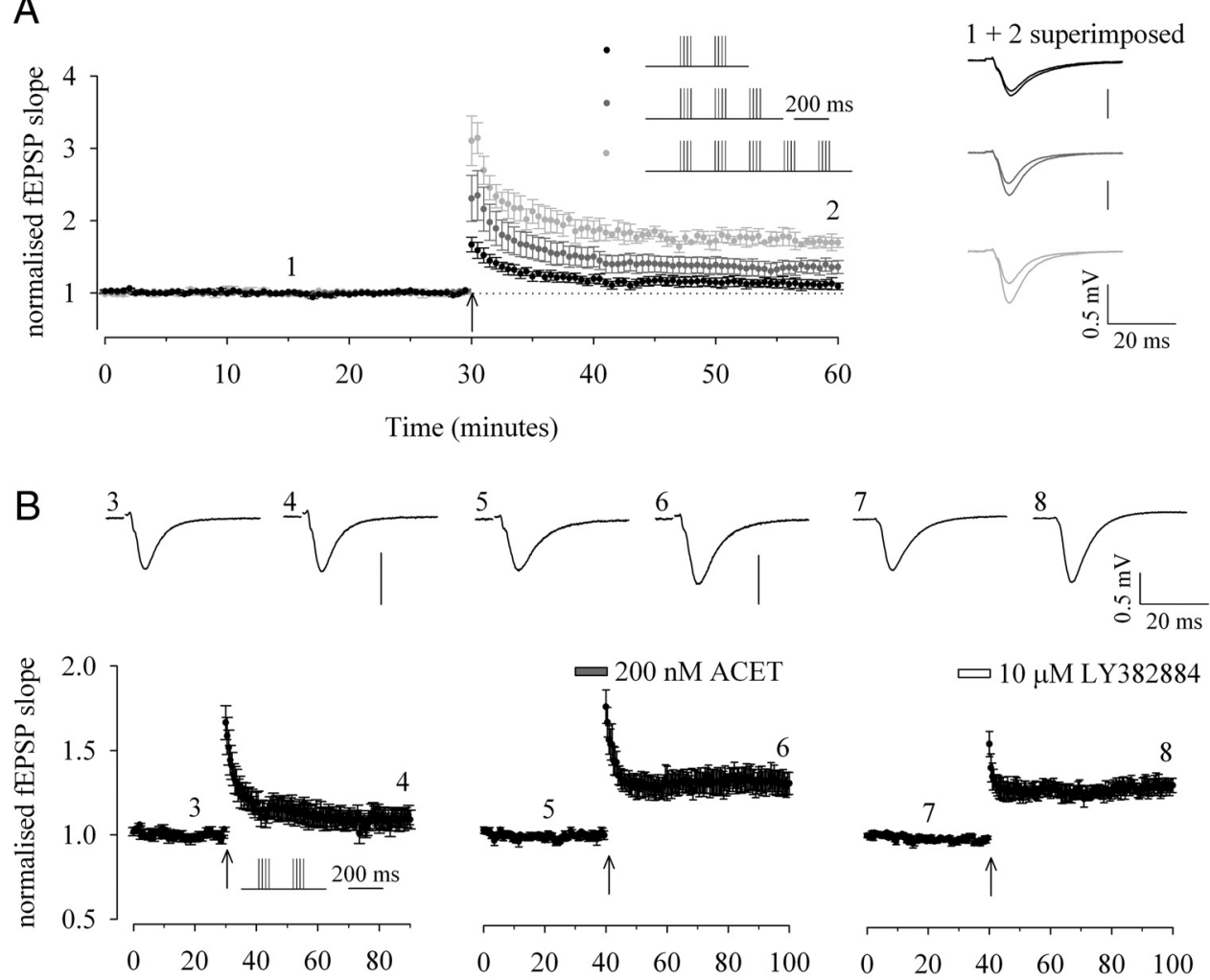

Time (minutes)

Figure 1. KAR antagonism lowers the threshold for induction of theta-burst LTP. A, Graph of pooled data to determine the threshold for induction of theta-burst LTP of fEPSPs recorded in naive slices. TBS paradigm consisted of four-pulse bursts at $50 \mathrm{~Hz}$ repeated either two (black; $n=9$ ), three (dark gray; $n=5$ ), or five times (light gray; $n=5$ ) at a theta frequency of $5 \mathrm{~Hz}$, as illustrated. $B$, Graph of pooled data comparing the effects of a subthreshold TBS ( 4 shocks at $50 \mathrm{~Hz}$ repeated twice at $5 \mathrm{~Hz}$ ) under control conditions $(n=9)$ in the presence of $200 \mathrm{~nm}$ ACET $(n=8)$ and $10 \mu \mathrm{m}$ LY382884 ( $n=6)$ in naive slices. In this and Figure 2, pooled data are accompanied by traces from a single representative example from time points indicated.

a subset of Schaffer collateral-commissural pathway (SCCP)interneuron synapses. By providing significant excitatory drive to these interneurons, KARs exert powerful control over levels of feedforward GABAergic transmission onto CA1 pyramidal neurons and, thereby, raise the threshold for induction of theta-burst LTP. As such, they play a critical physiological role in the regulation of NMDAR-dependent LTP to natural-like stimulus paradigms.

\section{Materials and Methods}

Parasagittal slices (400 $\mu \mathrm{m}$ thick) were prepared from Wistar rats of either sex (100-120 g for experiments with extracellular recordings and postnatal day 14 for whole-cell voltage clamp). Tissue was cut in ice-cold artificial CSF (aCSF) comprising (in $\mathrm{mM}$ ) the following: $124 \mathrm{NaCl}, 10$ D-glucose, 26 $\mathrm{NaHCO}_{3}, 3 \mathrm{KCl}, 1.25 \mathrm{NaH}_{2} \mathrm{PO}_{4}, 2 \mathrm{CaCl}_{2}$, and $1 \mathrm{MgSO}_{4}$ saturated with $95 \%$ $\mathrm{O}_{2}$ and $5 \% \mathrm{CO}_{2}$. For all recordings, the CA3 area was removed surgically. Slices were left to recover for $\geq 40 \mathrm{~min}$ and then transferred to either an interface recording chamber (extracellular) or a submerged chamber (whole-cell recordings). They were maintained at $30-32^{\circ} \mathrm{C}$ and perfused with aCSF at a rate of $1.8-2.2 \mathrm{ml} / \mathrm{min}$. Synaptic responses were evoked at low frequency (i.e., every $15 \mathrm{~s}$ for whole-cell and $30 \mathrm{~s}$ for extracellular experiments) by stimulating a bipolar electrode (nickel-chromium wire) positioned within the SCCP. These responses were collected for online analysis using LTP software (Anderson and Collingridge, 2007; www.winltp.com).

Field EPSPs (fEPSPs) were recorded using $4 \mathrm{~m} \mathrm{NaCl}$-filled electrodes (resistance, $\sim 2-4 \mathrm{M} \Omega$ ) positioned within the stratum radiatum (sRad) as described previously (Dargan et al., 2009). The slope of the initial rising phase of fEPSPs $(20-80 \%)$ was used as a measure of synaptic efficacy and the stimulation intensity was adjusted such that the baseline fEPSP amplitude was $\sim 20-40 \%$ of the maximal intensity that resulted in the appearance of a population spike. LTP was assessed by a TBS para- digm that consisted of four-pulse bursts ( $50 \mathrm{~Hz}$; i.e., every $20 \mathrm{~ms}$ ) separated at theta frequency ( $5 \mathrm{~Hz}$; i.e., every $200 \mathrm{~ms}$ ) and repeated two, three, or five times. Quantification of the levels of potentiation were made on the average of the last $10 \mathrm{~min}$ of the recording (50-60 min after TBS) except initial experiments to establish threshold (20-30 min; Fig. 1A).

Whole-cell recordings were made from visually identified [infrared differential interference contrast (DIC) optics] CA1 pyramidal neurons or interneurons located within the sRad. For whole-cell voltage-clamp recordings, patch electrodes (2-5 M $\Omega$ ) contained the following (in $\mathrm{mM}$ ): 130 $\mathrm{CsMeSO}_{4}$, 10 HEPES, 0.5 EGTA, 4 Mg-ATP, $0.3 \mathrm{Na}$-GTP, 5 QX-314, 8 $\mathrm{NaCl}, 275 \pm 5 \mathrm{mOsm}, \mathrm{pH}$ 7.2. Series resistance $\left(R_{\mathrm{s}}\right)$ was monitored by measuring the peak amplitude of the fast whole-cell capacitance current in response to a $5 \mathrm{mV}$ step. The amplitude was estimated by fitting a double exponential to the capacitance transient and determining the current at the beginning of the step. Only experiments where $R_{\mathrm{s}}<30 \mathrm{M} \Omega$, and with $<20 \%$ change in $R_{\mathrm{s}}$ during the course of the experiment, were included for analysis. EPSCs were recorded at a holding membrane potential of $-70 \mathrm{mV}$ in the presence of picrotoxin $(100 \mu \mathrm{M})$ and D-(-)-2-amino-5-phosphonopentanoic acid (D-AP5) (50 $\mu \mathrm{M})$ to antagonize fast $\mathrm{GABA}_{\mathrm{A}}$ and NMDAR-mediated components of synaptic transmission, respectively. This perfusate was supplemented further with bicuculline $(20 \mu \mathrm{M})$ and trans-2-carboxy-5,7-dichloro-5,7dichloro-4-phenylaminocarbonylamino-1,2,3,4-tetrahydroquinoline (L-689,560; $5 \mu \mathrm{M})$ in experiments where AMPAR and KAR-mediated EPSCs were pharmacologically isolated. IPSCs were recorded in the presence of D-AP5 (50 $\mu \mathrm{M})$ plus L-689,560 ( $5 \mu \mathrm{M})$ to antagonize NMDAR transmission with the cells held at $0 \mathrm{mV}$, the reversal potential for AMPAR-mediated events.

For whole-cell current-clamp recordings, patch electrodes (2-5 M $\Omega$ ) contained the following (in mM): $130 \mathrm{~K}$-gluconate, 10 HEPES, 0.5 EGTA, 4 
Mg-ATP, $0.3 \mathrm{Na}$-GTP, $7 \mathrm{NaCl}, 275 \pm 5$ mOsm, pH 7.2. Recordings were performed in bridge balance mode. Input resistance and spike frequency adaptation were monitored by passing square-wave current pulses (amplitude, $\pm 20-100 \mathrm{pA}$; duration, $500 \mathrm{~ms}$ ) to hyperpolarize and depolarize the neuron, respectively. The initial resting membrane potential and input resistance was measured at 0 DC current injection immediately after whole-cell access was obtained. Evoked excitatory and IPSPs (EPSP-IPSP sequence) were recorded at a potential slightly more hyperpolarized than the resting membrane potential by current injection $(\sim 20-50 \mathrm{pA})$ and in the presence of NMDAR antagonists D-AP5 (50 $\mu \mathrm{M})$ and L-689,560 (5 $\mu \mathrm{M})$.

In both whole-cell voltage and current-clamp recordings, all membrane potentials were corrected for the calculated liquid junction potential. Interneuron cell types were confirmed by the inclusion of $0.4 \%(\mathrm{w} / \mathrm{v})$ biocytin and subsequent post hoc morphological identification. All data were normalized to a period of baseline stability (5-10 min for whole-cell experiments; $30 \mathrm{~min}$ for extracellular experiments). All pooled data are expressed as mean \pm SEM. The rise time and decay time constant of evoked current responses were calculated offline using MiniAnalysis (Synaptosoft). Postsynaptic currents were aligned to 50\% rise time and averaged. Rise time (10-90\%) and decays $(90-10 \%)$ were then calculated. Decays were fitted with either a single $\left(\mathrm{Ae}^{-t / \tau}\right)$ or double exponential $\left(A_{1} e^{-t / \tau}{ }_{1}+A_{2} e^{-t / \tau}\right)$, where $A_{n}$ represents the current amplitude corresponding to the nth decay time constant. The goodnessof-fit was assessed by comparing the SD of the fit. For those responses best fit by a double exponential, an overall weighted decay constant $\left(\tau_{\mathrm{w}}\right)$ was calculated using the expression $\tau_{\mathrm{w}}=\tau_{1}{ }^{*} A_{1} /\left(A_{1}+A_{2}\right)+\tau_{2}^{*} A_{2} /\left(A_{1}\right.$ $+A_{2}$ ). Facilitation ratios were measured from averages of $\geq 5$ traces relative to the amplitude of the first evoked response (EPSC or IPSC). Any summation of postsynaptic currents during high-frequency bursts was removed by scaling an averaged response to low-frequency stimulation to the peak of the first recorded response in the train and subtracting it from the original trace. This process was then repeated sequentially for all postsynaptic currents in the train. Statistical significance was routinely tested using paired and unpaired Student's $t$ tests and ANOVA with post hoc Bonferroni correction as appropriate. Datasets relating to AP firing were not normally distributed (i.e., failed the Shapiro-Wilk's $W$ test) and either a Wilcoxon signed-rank or Mann-Whitney test, for paired and unpaired data respectively, were used. In all cases, $p<0.05$ was considered significant.

Identification of interneurons. Whole-cell patch-clamp recordings were made from a total of 52 interneurons located within the distal half of sRad. Large cell bodies were clearly visible under DIC optics and care was taken to avoid any pyramidal-like somata with or without obvious prominent bifurcating apical dendrites because these are more likely to be radiatum giant cells (Gulyás et al., 1998). Biocytin was included in the patch solution allowing post hoc morphological characterization. Some experimental protocols were altered (e.g., baselines reduced to $5 \mathrm{~min}$; no washout of drugs) to minimize the length of recording and preserve the health of the neuron. Slices were fixed in a $4 \%$ paraformaldehyde-phosphate buffered solution (PFA-PBS), then washed and stored in PBS at $+4^{\circ} \mathrm{C}$. Slices were subsequently washed in $0.3 \%$ Triton-X-PBS (PBS-T) and incubated in $0.4 \%$ normal goat serumPBS-T containing $3 \mu \mathrm{g} / \mathrm{ml}$ Alexa 568 -avidin for $2 \mathrm{~h}$ at room temperature. PBS-washed slices were mounted onto slides and fluorescent interneurons visualized by confocal laser scanning microscopy (Zeiss LSM 5 Pascal with Axioplan 2 microscope). In the majority of reconstructed interneurons, ovoid or fusiform somata gave rise to $2-5$ visible arborizations that were largely confined to the radiatum; morphologically these cells closely resembled Schaffer collateral-associated cells (SCAs) (Vida et al., 1998; Cope et al., 2002; Pawelzik et al., 2002; Ali, 2007).

All compounds were purchased from Tocris Bioscience except Alexa 568-avidin, which was from Sigma-Aldrich, and LY382884 and ACET, which were kind gifts from Dr David Bleakman (Eli Lilly) and Prof. David Jane (University of Bristol), respectively.

\section{Results}

Synaptic activation of KARs raises the threshold for induction of theta-burst LTP

The role of KARs on theta-burst LTP was studied by recording extracellular fEPSPs in area CA1 in response to SCCP stimula- tion. We first established the threshold for the induction of thetaburst LTP under our recording conditions. A protocol of two bursts (with each burst comprising 4 pulses at $50 \mathrm{~Hz}$ ) at an interval of $200 \mathrm{~ms}$ was subthreshold for the generation of LTP, whereas three or five bursts at this frequency reliably induced significant LTP. The mean potentiation after TBS was $11 \pm 6 \%$ $(n=9 ; p>0.05), 36 \pm 8 \%$, and $70 \pm 8 \%$, respectively (both $n=$ $5 ; p<0.05$; Fig. $1 A)$. In the presence of the KAR antagonist (S)-1-(2-amino-2-carboxyethyl)-3-(2-carboxy-5-phenylthiophene-3yl-methyl)-5-methylpyrimidine-2,4-dione (ACET; $200 \mathrm{nM}$ ), however, the two-burst protocol resulted in significant potentiation. Mean potentiation after TBS in ACET was $30 \pm 6 \%(n=8)$ compared with $9 \pm 5 \%(n=9)$ in interleaved control experiments $(p<0.05$; Fig. $1 B)$. Further studies suggest that ACET, while selective for GluK1 subunit-containing KARs (Dolman et al., 2007; Dargan et al., 2009), may also have some potency at non-GluK1-containing KARs (Perrais et al., 2009, Pinheiro et al., 2012). Therefore, we repeated this finding with the structurally unrelated GluK1 subunit-containing KAR antagonist (3S, 4aR, 6S, 8aR)-[(4-carboxyphenyl)methyl]-1,2,3,4,4a,5,6, 7,8,8a-decahydroisoquinoline-3-carboxylic acid (LY382884) (Bortolotto et al., 1999). In an analogous manner to that seen with ACET, mean potentiation after TBS in LY382884 (10 $\mu \mathrm{M})$ was $31 \pm 5 \%(n=6 ; p<0.05$; Fig. $1 B)$. Thus, in the absence of KAR activation, a protocol that is clearly subthreshold to generate LTP under control conditions is converted into one that now generates sufficient NMDAR activation to result in significant potentiation. The antagonist pharmacology is consistent with a role for GluK1 subunit-containing KARs in underlying this phenomenon.

The contribution of $\mathrm{GABA}_{\mathrm{A}}$ receptor $\left(\mathrm{GABA}_{\mathrm{A}} \mathrm{R}\right)$-mediated inhibition was tested pharmacologically by applying bicuculline $(20 \mu \mathrm{M})$. In the presence of this compound, the previously subthreshold protocol for the induction of theta-burst LTP resulted in significant potentiation in both interleaved control experiments and in the presence of ACET. Mean potentiation after TBS was $43 \pm 5 \%(n=4 ; p<0.05)$ and $40 \pm 6 \%(n=4 ; p<0.05)$, respectively (Fig. $2 \mathrm{~A}$ ). There was no significant difference between the amounts of potentiation under these two experimental conditions $(p>0.05)$. Thus, bicuculline mimics and fully occludes the effects of ACET on TBS. To determine whether antagonism of $\mathrm{GABA}_{\mathrm{A}}$ Rs blocked the ability of ACET to lower the threshold for LTP induction, we reduced the number of stimulations within each burst from four to two at $50 \mathrm{~Hz}$. In the presence of bicuculline, this modified protocol of two bursts (with each burst now comprising only 2 pulses at $50 \mathrm{~Hz}$ ) at an interval of 200 ms was subthreshold for the generation of LTP. Furthermore, when repeated in interleaved experiments, ACET no longer had any effect on this level of potentiation. Thus, the mean change in fEPSP slope after LTP induction was $-5 \pm 3 \%$ and $-5 \pm 2 \%$ (both $n=5$; $p>0.05$; Fig. $2 B$ ), respectively.

These data indicate that the effect of ACET on the threshold for induction of theta-burst LTP is most likely due to an effect of KARs to alter the balance between excitatory and GABAergic transmission onto CA1 pyramidal neurons during TBS. This could be due to the presence of presynaptic KARs at SCCP or interneuron terminals functioning either in a homosynaptic or heterosynaptic manner, respectively. Furthermore, such a mechanism could occur at inputs onto CA1 pyramidal neurons or at synapses to the interneurons themselves. Finally, KARs could provide postsynaptic excitatory drive to interneurons. The predicted outcome of KAR antagonism would be to compromise GABAergic transmission during TBS such that the threshold for 
A<smiles>CCCCI</smiles><smiles>C=CCCC</smiles><smiles>CCCCC</smiles>
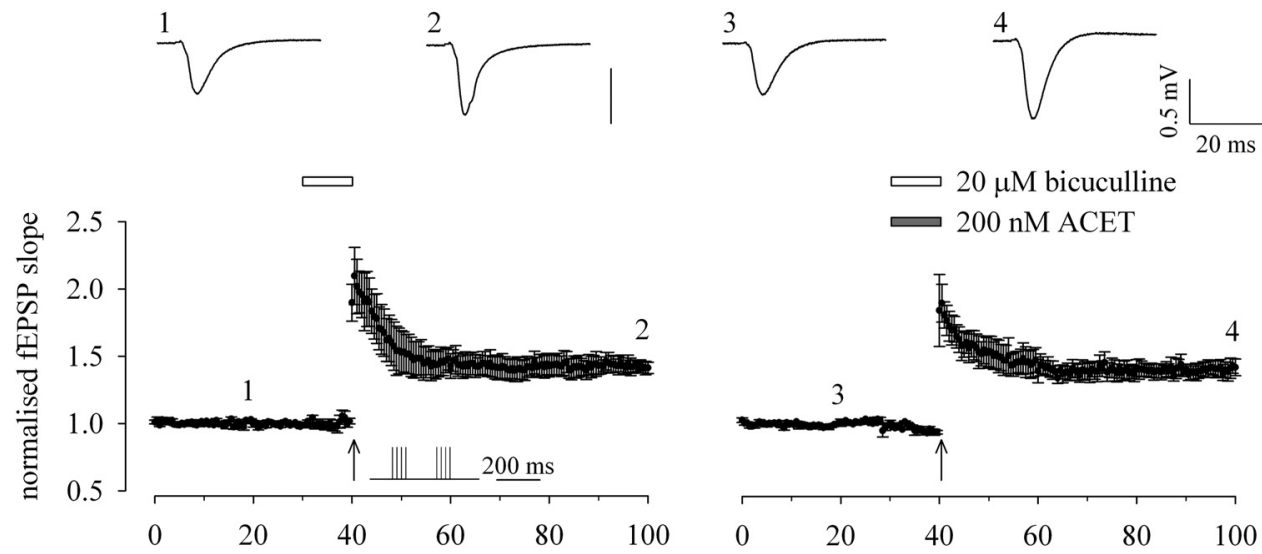

Time (minutes)

B
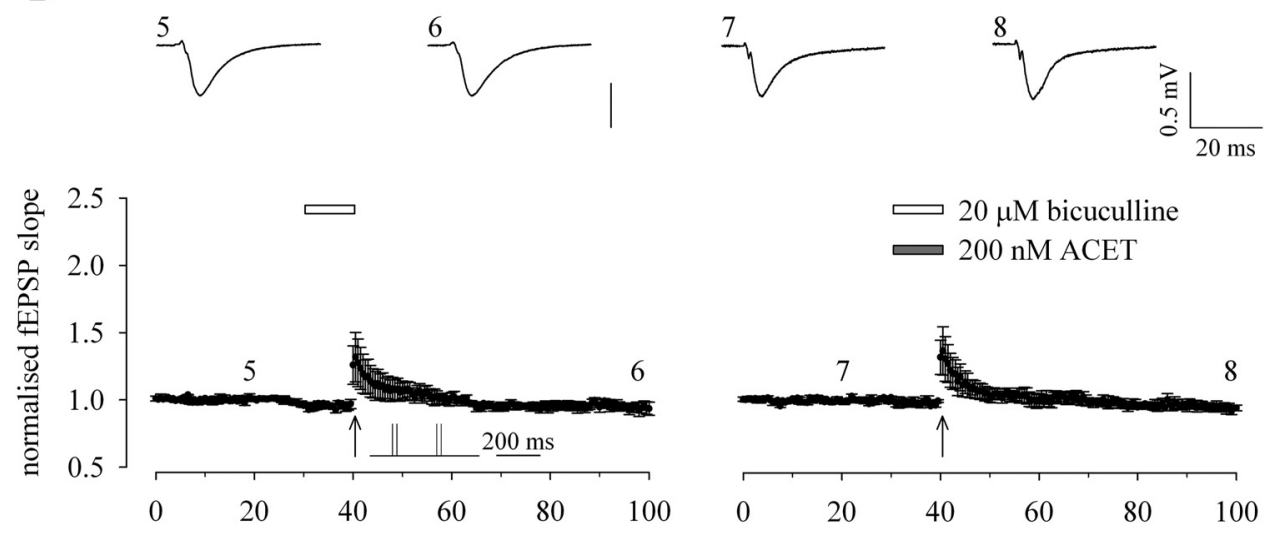

Time (minutes)

Figure 2. The effect of ACET on theta-burst LTP is occluded and blocked by GABA $A_{A} R$ antagonism. $A, B$, Graph of pooled data comparing the effects of $(A)$ TBS ( 4 shocks at $50 \mathrm{~Hz}$ repeated twice at $5 \mathrm{~Hz}$; both $n=4)$ and $(B)$ a modified induction protocol (2 shocks at $50 \mathrm{~Hz}$ repeated twice at $5 \mathrm{~Hz}$; both $n=5$ ) on fEPSPs in the presence of $20 \mu \mathrm{m}$ bicuculline, a GABA $\mathrm{R}$ antagonist and in the combined presence of $20 \mu \mathrm{m}$ bicuculline and $200 \mathrm{~nm}$ ACET, respectively.

LTP induction is lowered. The following experiments were designed to investigate the localization of KARs that are synaptically activated during TBS in the CA1 circuitry.

\section{KARs do not modulate excitatory synaptic transmission or monosynaptically evoked GABAergic transmission onto CA1 pyramidal neurons}

We made whole-cell patch-clamp recordings from CA1 pyramidal neurons to examine the effect of ACET on evoked excitatory and monosynaptically evoked GABAergic synaptic transmission (EPSCs and IPSCs). Responses were evoked by stimulation of the SCCP at low frequency with interspersed test protocols of TBS, comprising two bursts of four pulses at $50 \mathrm{~Hz}$ at an interburst interval of $200 \mathrm{~ms}$.

To record EPSCs, NMDAR and $\mathrm{GABA}_{\mathrm{A}} \mathrm{R}$-mediated conductances were blocked by D-AP5 $(50 \mu \mathrm{M})$ and picrotoxin (100 $\mu \mathrm{M})$, respectively; postsynaptic $\mathrm{GABA}_{\mathrm{B}} \mathrm{R}$-mediated events were eliminated by use of a $\mathrm{Cs}^{+}$-based filling solution. The resultant evoked EPSCs had an average amplitude of $62 \pm 6$ $\mathrm{pA}$, a rise time of $3.5 \pm 0.2 \mathrm{~ms}$, and were best fit by a single exponential with a decay time constant of $12.5 \pm 0.2 \mathrm{~ms}(n=$ $5)$. ACET (200 nM) had no effect on EPSCs evoked at low frequency $(-3 \pm 3 \% ; p>0.05)$, TBS train area $(+8 \pm 7 \% ; p>$ 0.05 ), or EPSC facilitation (Fig. $3 A-C ; n=5$ ).
IPSCs were recorded in the presence of D-AP5 (50 $\mu \mathrm{M})$ plus L-689,560 $(5 \mu \mathrm{M})$ to block the NMDAR-mediated component of EPSCs; cells were held at $0 \mathrm{mV}$, the reversal potential for AMPAR-mediated currents. As postsynaptic GABA $_{B} \mathrm{R}$-mediated events were eliminated by use of a $\mathrm{Cs}^{+}$-based filling solution, the evoked outward currents represent $\mathrm{GABA}_{\mathrm{A}} \mathrm{R}$-mediated events. The stimulation electrode was placed close $(<0.5 \mathrm{~mm})$ to the recording site to evoke GABAergic responses monosynaptically by direct stimulation of interneuron fibers. Evoked IPSCs had an average amplitude of $76 \pm 14 \mathrm{pA}$ and a rise time of $2.6 \pm 0.3 \mathrm{~ms}$, with a double exponential $\tau_{\mathrm{w}}$ of $32.6 \pm 3.2 \mathrm{~ms}(n=6)$. ACET $(200$ nM) had no significant effects on monosynaptically evoked IPSC amplitude $(-9 \pm 12 \% ; p>0.05)$, charge transfer $(-10 \pm 7 \%$; $p>0.05)$, rise times $(-6 \pm 5 \% ; p>0.05$; data not shown), or weighted decay $(+8 \pm 14 \%$; $p>0.05$; data not shown). In addition, there was no change in IPSC area throughout the train $(-9 \pm 12 \% ; p>0.05)$. Application of 2,3-dioxo-6-nitro-1,2,3,4tetrahydrobenzo[f] quinoxaline-7-sulfonamide (NBQX; $1 \mu \mathrm{M}$ ), at a dose selective for AMPAR antagonism, had no effect on IPSC amplitude $(-10 \pm 7 \%$; $p>0.05)$, confirming that these events were monosynaptic and not disynaptic in origin. A subsequent application of bicuculline $(20 \mu \mathrm{M})$ abolished IPSC amplitude (by $100 \pm 2 \% ; p<0.05)$, proving that the recorded events were mediated by $\mathrm{GABA}_{\mathrm{A}}$ Rs (Fig. $3 D-F ; n=6$ ). 
A

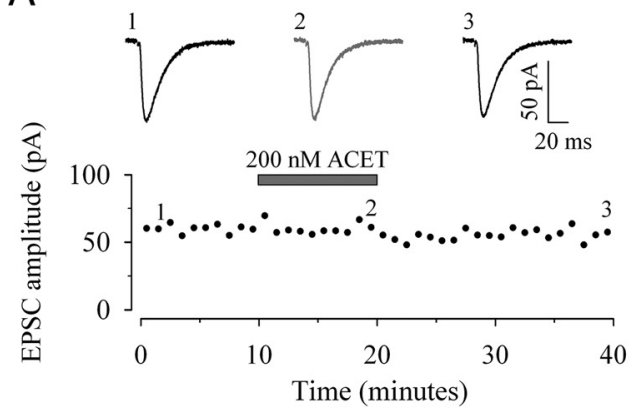

C
B
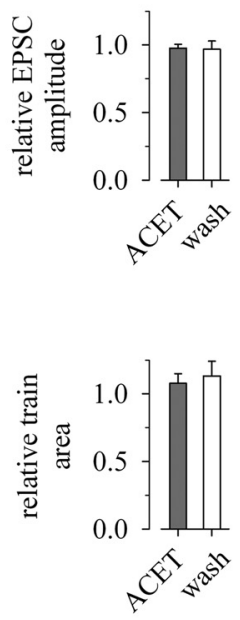

D

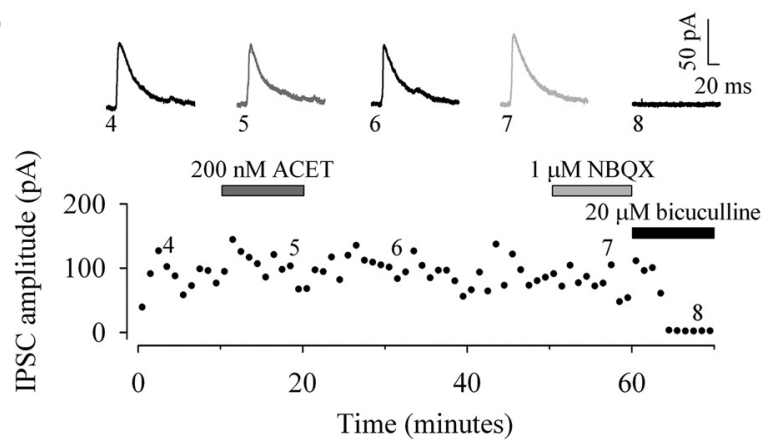

$\mathrm{E}$

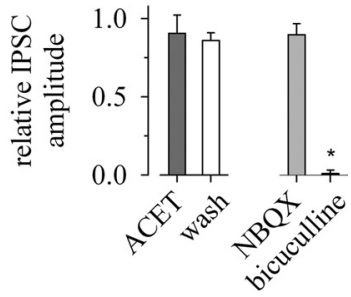

$\mathrm{F}$
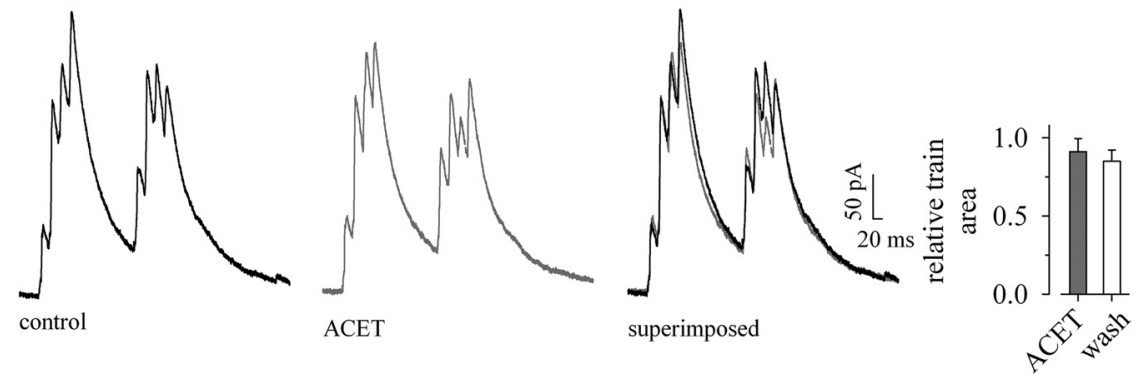

Figure 3. ACET has no effect on either evoked excitatory or monosynaptic GABAergic synaptic transmission onto CA1 pyramidal neurons. AMPAR-mediated EPSCs recorded in the presence of D-AP5 $(50 \mu \mathrm{M})$ and picrotoxin $(100 \mu \mathrm{M})$ with CA1 pyramidal neurons voltage-clamped at $-70 \mathrm{mV}$. $\boldsymbol{A}, \boldsymbol{B}, \mathrm{A}$ single representative example $(\boldsymbol{A})$ and pooled data $(n=5)(\boldsymbol{B})$ to illustrate $200 \mathrm{~nm}$ ACET (dark gray) has no effect on EPSCs evoked at low frequency. C, ACET has no effect on EPSC facilitation during TBS (4 shocks at $50 \mathrm{~Hz}$ delivered twice at $5 \mathrm{~Hz}$ ) with pooled data showing no change in relative charge transfer control $(n=5)$. GABAergic responses are recorded in the presence of D-AP5 $(50 \mu \mathrm{M})$ and L-689,560 (5 $\mu \mathrm{M})$ with neurons voltage-clamped at $0 \mathrm{mV} . \boldsymbol{D}, \boldsymbol{E}$, A single example $(\boldsymbol{D})$ and pooled data $(n=6)(\boldsymbol{E})$ to demonstrate the lack of effect of ACET (dark gray) or NBQX (light gray) on monosynaptic IPSCs evoked at low frequency. The latter together with the proximity of stimulation and bicuculline-sensitivity implies events are monosynaptically evoked GABA $R$-mediated events. $F$, Pooled data showing no reduction in the relative charge transfer in the presence of ACET during TBS $(n=6)$. Unless otherwise indicated, in this and subsequent figures of whole-cell data, individual time plots illustrate a typical experiment (1-min bins) accompanied by representative synaptic current traces from the time points indicated; the TBS examples are taken from the same experiment; pooled data are illustrated by bar charts plotting the mean \pm SEM.

Thus, ACET has no effect on either excitatory or monosynaptically evoked GABAergic synaptic transmission onto principal neurons. This argues against any involvement of presynaptic KARs, acting either in a homomeric or heteromeric fashion at SCCP-CA1 or interneuron-CA1 synapses, respectively, in the ability of ACET to lower the threshold for induction of thetaburst LTP.

\section{KARs provide significant excitatory synaptic drive to a} subpopulation of sRad interneurons

We next studied whether KARs could provide direct excitatory drive to CA1 sRad interneurons. Interneuronal EPSCs were evoked by weak stimulation of the SCCP at low frequency with interspersed test protocols of TBS, in the presence of D-AP5 (50 $\mu \mathrm{M})$ plus L-689,560 (5 $\mu \mathrm{M})$ and picrotoxin $(100 \mu \mathrm{M})$ plus bicuculline $(20 \mu \mathrm{M})$, and $\mathrm{Cs}^{+}$in 
A
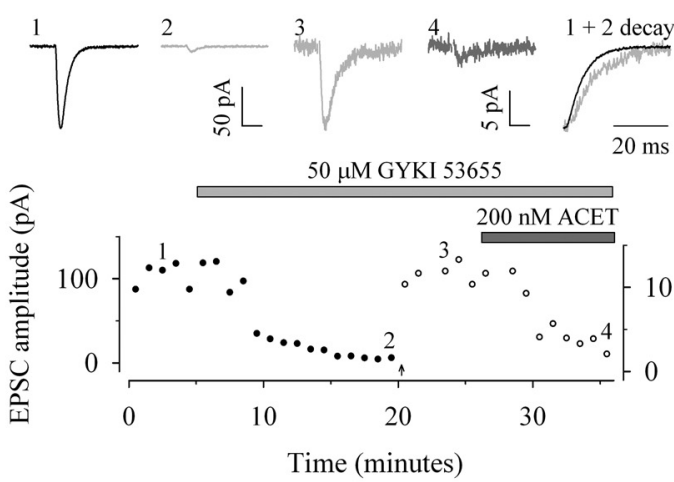

C

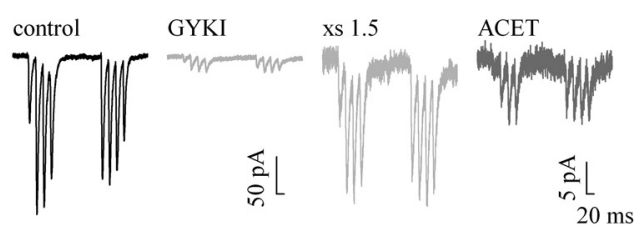

就

0.0
B

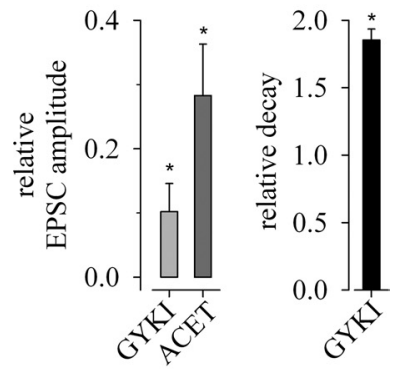

E

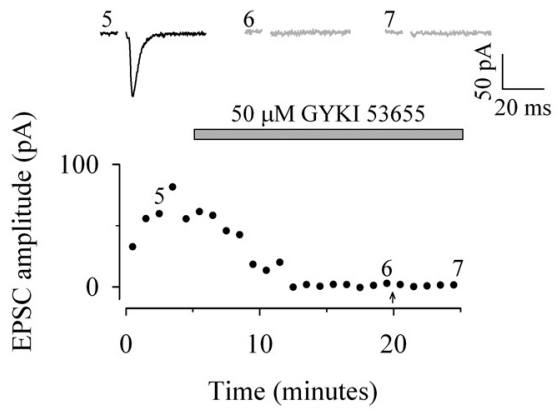

G

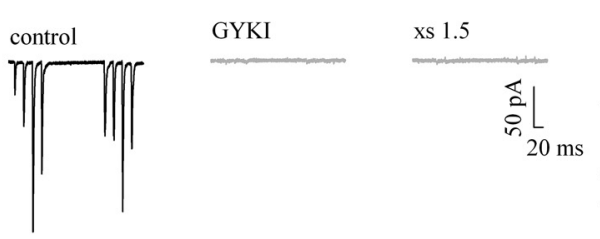

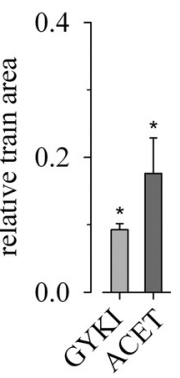

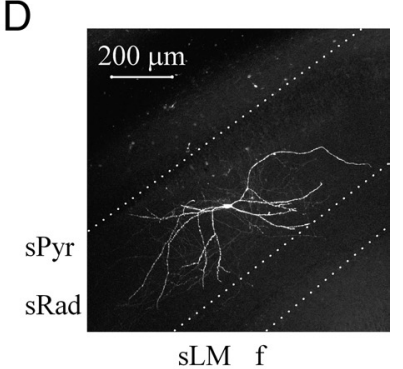

F
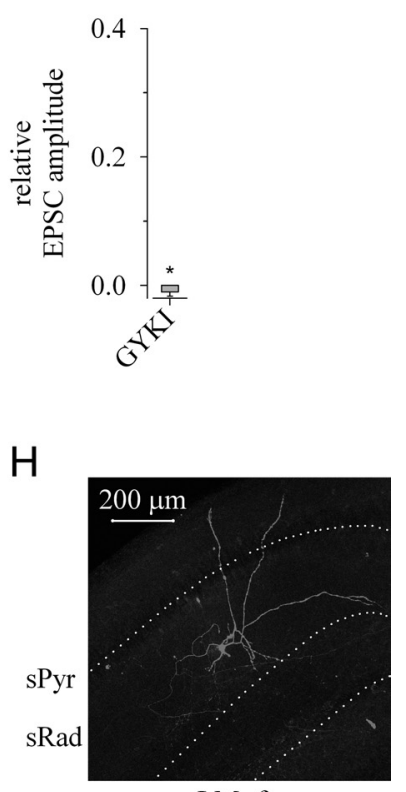

sLM f

Figure 4. Selective AMPAR antagonism uncovers a KAR-mediated component of excitatory synaptic transmission in a subset of sRad interneurons. EPSCS are recorded in the presence of D-AP5 (50 $\mu \mathrm{M})$ plus $\mathrm{L}-689,560(5 \mu \mathrm{m})$ and picrotoxin $(100 \mu \mathrm{m})$ plus bicuculline $(20 \mu \mathrm{m})$ to block NMDAR and GABA $A_{A}$ R-mediated components of synaptic transmission, respectively; CA1 interneurons were voltage-clamped at - 70 $\mathrm{mV} . \boldsymbol{A}, \boldsymbol{B}$, A single example $(\boldsymbol{A})$ and pooled data $(\boldsymbol{B})$ to demonstrate the effect of an application of GYKI 53655 (gray) and ACET (dark gray) on low-frequency evoked EPSC amplitude and relative decay. At the time point indicated by an arrow, the stimulus intensity was increased by $50 \%$ (i.e., $\times 1.5$ ) and is subsequently shown on an expanded scale (open circles; right ordinate); note that the corresponding single examples of EPSCs are also now illustrated on an expanded $y$-axis for clarity. C, Pooled data illustrating the effect of GYKI 53655 and ACET on charge transfer during TBS $(n=6)$. $\boldsymbol{D}$, Biocytin-filled sRad interneuron with KAR-mediated EPSC. $\boldsymbol{E}-\boldsymbol{G}$, A single example $(\boldsymbol{E})$ and pooled data $(\boldsymbol{F})$ to illustrate that GYKI 53655 completely abolishes evoked EPSCs and $(\boldsymbol{G})$ charge transfer during TBS in a separate population of interneurons $(n=6)$. H, Biocytin-filled sRad interneuron with no KAR-mediated EPSC. sPyr, stratum pyramidale; sRad, stratum radiatum; sLM, stratum lacunosum-moleculare; f, hippocampal fissure.

the electrode filling solution. On average, these baseline EPSCs had an amplitude of $26 \pm 1 \mathrm{pA}$ with a rise time of $1.4 \pm 0.2 \mathrm{~ms}$ and a decay time constant of $4.0 \pm 0.3 \mathrm{~ms}(n=24)$.

In 12 interneurons, we applied 1-(4-aminophenyl)-3methylcarbamyl-4-methyl-7,8-methylenedioxy-3,4-dihydro-
5H-2,3-benzodiazepine (GYKI 53655; $50 \mu \mathrm{M}$ ), a selective noncompetitive antagonist of AMPA receptors. GYKI 53655 depressed excitatory synaptic transmission to both singleshock and TBS trains in all interneurons. In 6 of 12 interneurons (Fig. $4 A-D$ ), EPSC amplitude and total charge transfer during 
TBS, although significantly depressed, were not completely abolished (by $90 \pm 4 \%$ and $91 \pm 1 \%$, respectively; $p<0.05$ ). This depression was surmountable with increasing stimulus and stable thereafter. Rise times were not significantly affected by the presence of GYKI 53655 ( $+20 \pm 12 \%$; $p>0.05$; data not shown). In contrast, the decay time constant of the residual response was significantly slower than control $(+85 \pm 8 \%$; $p<0.05)$. A subsequent application of ACET (200 nM) depressed both EPSC amplitude and TBS area (by $72 \pm 10 \%$ and $82 \pm 5 \%$, respectively; $p<0.05)$, indicating that a significant component of the residual EPSC was mediated by KARs.

In the remaining 6 of 12 interneurons (Fig. $4 \mathrm{E}-\mathrm{H}$ ), EPSCs and TBS charge transfer were completely abolished (by $101 \pm 1 \%$ and $97 \pm 1 \%$, respectively; $p<0.05$ ) by GYKI 53655. Furthermore, the noncompetitive antagonism provided by this dose of antagonist was nonsurmountable and increasing the stimulus intensity by $50 \%$ did not recover any postsynaptic response $(p>0.05)$.

We also examined the effect of an application of ACET alone in a separate set of interneurons. ACET (200 nM; $10 \mathrm{~min})$ depressed evoked excitatory synaptic transmission to both singleshock and TBS trains in a significant proportion (5 of 12) of interneurons (Fig. 5A-D); EPSC amplitude and total charge transfer during TBS were significantly depressed (by $20 \pm 4 \%$ and $27 \pm 3 \%$, respectively; $p<0.05)$. While, EPSC rise times were unaffected $(+1 \pm 13 \% ; p>0.05)$, decay time constants were decreased significantly (by $26 \pm 6 \% ; p<0.05$ ). These effects were reversible following a $20 \mathrm{~min}$ washout of ACET. Finally, in this subpopulation of interneurons, ACET had no effect on the facilitation of EPSCs during TBS (Fig. 5C). In contrast, the same application of ACET failed to elicit any significant effect on EPSCs in the remaining (7 of 12) interneurons (data not shown).

Together, the effects of GYKI 53655 and ACET suggest a significant proportion $(\sim 45 \%)$ of interneurons within the distal part of area CA1 support both AMPAR and KARmediated excitatory synaptic transmission in response to SCCP stimulation. Furthermore, the lack of any effect of ACET on overall levels of facilitation during TBS trains in either population imply no role for ACET-sensitive presynaptic KARs in altering the dynamics of excitatory synaptic transmission at these synapses.

\section{KAR blockade has no effect on monosynaptic IPSCs in sRad interneurons}

KARs are proposed to regulate GABA release onto both CA1 pyramidal neurons (Min et al., 1999) and at synapses onto other interneurons (Cossart et al., 2001). Therefore, we next studied the possible contribution of physiologically activated KARs on GABAergic transmission onto interneurons. Monosynaptic IPSCs were pharmacologically isolated by D-AP5 $(50 \mu \mathrm{M})$ plus L-689,560 (5 $\mu \mathrm{M})$ and GYKI $53655(50 \mu \mathrm{M})$ and evoked by stimulating close to the recording site while holding the neuron at 0 $\mathrm{mV}$ in a total of seven sRad interneurons. Evoked IPSCs had an average amplitude of $37 \pm 7 \mathrm{pA}$ and a rise time of $2.0 \pm 0.2 \mathrm{~ms}$, with a double exponential weighted decay time constant of $32.2 \pm 4.9 \mathrm{~ms}$. ACET (200 nM; $10 \mathrm{~min}$ ) had no effect on IPSC amplitude evoked at low frequency $(-4 \pm 14 \% ; p>0.05)$ or train area during the TBS protocol $(+2 \pm 13 \% ; p>0.05)$. There was little if any overall facilitation of IPSCs during TBS and total charge transfer during the trains did not alter following application of ACET (Fig. 5E-H). Thus, GluK1-containing KARs may play only a minor or no role in regulating GABAergic transmission onto sRad interneurons.
KAR-mediated excitatory synaptic transmission helps maintain all-or-none AP firing in a subpopulation of sRad interneurons

We made whole-cell current-clamp recordings from sRad interneurons to investigate the role of GluK1 subunit-containing KARs on both intrinsic excitability and firing patterns resulting from evoked excitatory synaptic transmission. These interneurons $(n=21)$ had a resting membrane potential of $57 \pm 1 \mathrm{mV}$, input resistance of $383 \pm 35 \mathrm{M} \Omega$, and displayed some spike frequency adaptation in response to depolarizing current steps (compare an initial to final firing frequency of $21.5 \pm 3.0$ to $14.6 \pm 1.1 \mathrm{~Hz}$, respectively, during a $500 \mathrm{~ms}$ step; $p<0.05)$. APs had a spike amplitude (from threshold to peak) of $58 \pm 2 \mathrm{mV}$ and spike width (at half-amplitude) of $1.60 \pm 0.07 \mathrm{~ms}$ and were followed by a prominent afterhyperpolarization of $13 \pm 1 \mathrm{mV}$ (Fig. $6 A$ ). Responses were evoked by stimulation of the SCCP at low frequency with interspersed test protocols of TBS in the presence of D-AP5 $(50 \mu \mathrm{M})$ plus L-689,560 $(5 \mu \mathrm{M})$ and CGP $55845(10 \mu \mathrm{M})$ to block NMDARs and $\mathrm{GABA}_{\mathrm{B}} \mathrm{Rs}$, respectively. Interneurons were then held at a potential slightly more hyperpolarized $(-67 \pm 1 \mathrm{mV})$ than the resting membrane potential by current injection $(\sim 20-50 \mathrm{pA})$ and the stimulus intensity was adjusted such that the amplitude of the resultant EPSP-IPSP was sufficient to cause AP firing in response to single shocks in $15-60 \%$ of trials. In this way, we examined the effect of KAR antagonism [with either ACET (200 nM; $n=11)$ or LY382884 (10 $\mu \mathrm{M} ; n=10)$ ] on both evoked EPSP amplitude and AP success rate, neuronal passive properties (such as membrane potential and input resistance), and intrinsic excitability (in response to depolarizing current steps). A single example of such an experiment is illustrated in Figure $6 B-D$. In these sets of experiments, interneurons were separated into two groups based solely on whether KAR antagonism depressed EPSP amplitude by $>10 \%$ or not (Fig. $6 E$ ). Fourteen of 21 cells (ACET: 7 of 11; LY382884: 7 of 10) fulfilled this simple criterion with EPSP amplitude significantly depressed (by $27 \pm 4 \% ; p<0.05$ ) with an associated concomitant reduction in both AP success rate to a single shock (from $0.39 \pm$ 0.06 to $0.06 \pm 0.02$, respectively; $p<0.05$ ) and the total number of APs generated during interspersed TBS protocols (from $4.0 \pm$ 0.7 to $2.2 \pm 0.7$, respectively; $p<0.05$ ). The remaining 7 of 21 showed no significant change in EPSP amplitude $(+6 \pm 4 \% ; p>$ 0.05 ) or spikes generated either per single shock (compare $0.30 \pm$ 0.05 to $0.36 \pm 0.08$, respectively; $p>0.05$ ) or per TBS protocol (compare $4.5 \pm 0.7$ to $3.8 \pm 0.6$, respectively; $p>0.05$ ) (Fig. $6 F$ ). These differences could not be attributed to any effect on either passive properties or intrinsic excitability of the recorded neurons because there was no significant change in membrane potential $(0.0 \pm 0.2 \mathrm{mV}$ vs $-0.1 \pm 0.3 \mathrm{mV})$, input resistance $(-6 \pm$ $3 \%$ vs $-8 \pm 3 \%$; data not shown), or excitability (percentage change in the average number of spikes per second during a depolarizing step: $-4 \pm 10 \%$ vs $0 \pm 15 \%$; Fig. $6 F$ ) following KAR antagonism in either GluK1 subunit-containing or GluK1 subunit-noncontaining population of interneurons, respectively.

These data support the idea that significant proportions of interneurons within the distal part of area CA1 have KARmediated postsynaptic drive and, furthermore, that these inputs contribute to the maintenance of AP firing in response to both single stimulation and during TBS protocols.

Post hoc morphological characterization showed that the majority (49 of 52) of the recorded interneurons had an ovoid or fusiform somata, each of which gave rise to $2-5$ visible arborizations largely confined to the radiatum; morphologically these cells closely resembled SCAs. The remaining three neurons had 
A

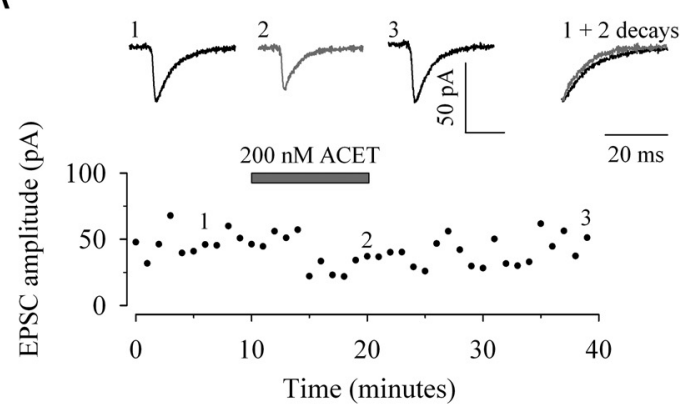

C

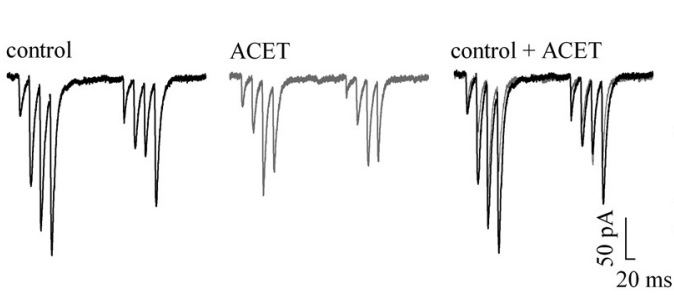

B

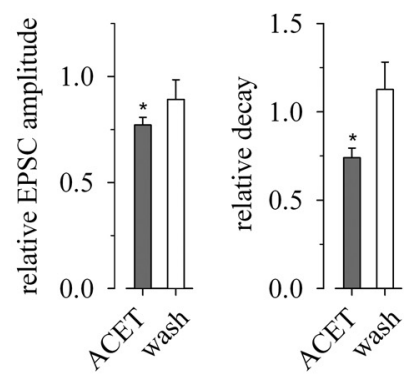

D

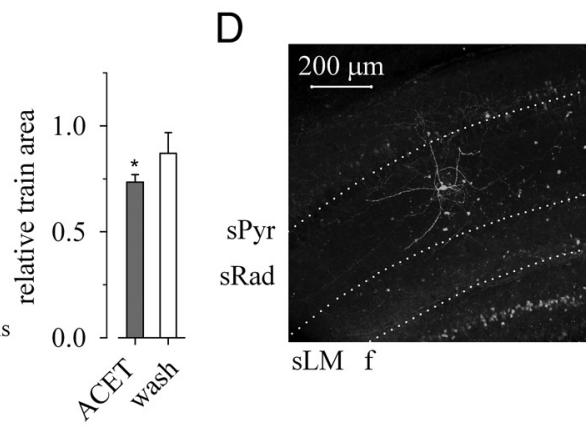

$E$

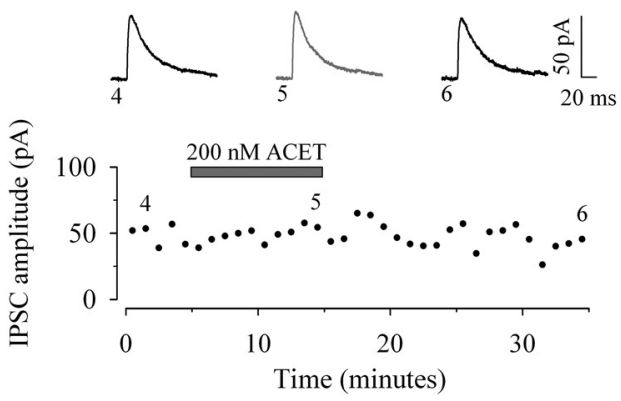

$\mathrm{F}$

G
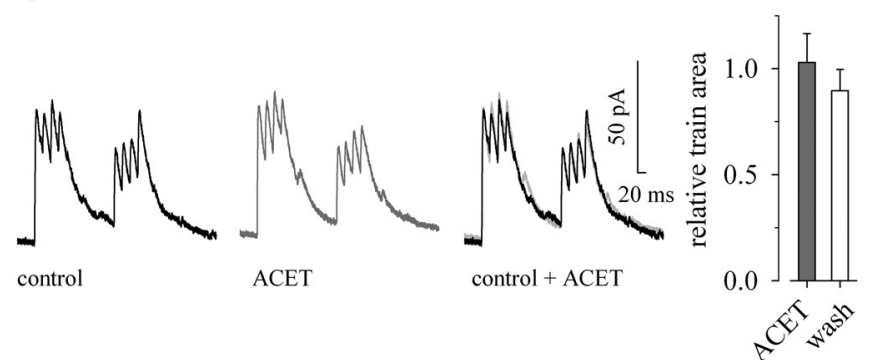

$\mathrm{H}$

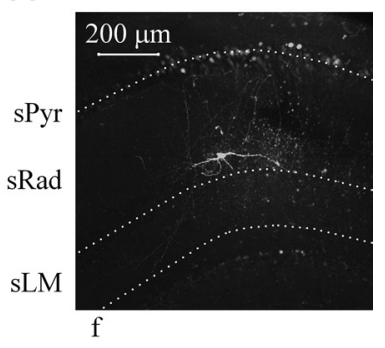

Figure 5. ACET attenuates excitatory synaptic transmission in a subset of sRad interneurons but has no effect on monosynaptically evoked GABAergic transmission onto such neurons. All EPSCs are recorded

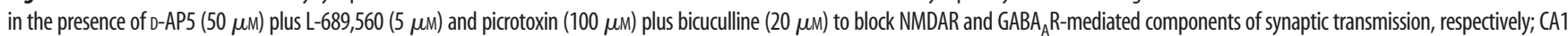
interneurons were voltage-clamped at $-70 \mathrm{mV}$. $\boldsymbol{A}-\boldsymbol{C}$, A single example $(\boldsymbol{A})$ and pooled data $(\boldsymbol{B})$ to illustrate the reversible effect of ACET (dark gray) on low-frequency evoked EPSCS, relative decay, and ( $\boldsymbol{C}$ ) charge transfer during TBS $(n=5)$. D, Biocytin-filled sRad interneuron with KAR-mediated EPSC. IPSCs are recorded in the presence of D-AP5 (50 $\mu \mathrm{M})$, L-689,560 (5 $\mu \mathrm{M})$, and GYKI 53655 (50 $\mu \mathrm{M})$ with neurons voltage-clamped at $0 \mathrm{mV}$. $\boldsymbol{E}-\mathbf{G}$, a single example $(\boldsymbol{E})$ and pooled data to illustrate the lack of any effects on $(\boldsymbol{F})$ IPSC amplitude and ( $\boldsymbol{G}$ ) charge transfer during TBS ( $n=7$ ). $\boldsymbol{H}$, Biocytin-filled sRad interneuron with ACET-insensitive monosynaptically evoked IPSC. sPyr, stratum pyramidale; sRad, stratum radiatum; sLM, stratum lacunosum-moleculare; $f$, hippocampal fissure.

cell bodies located within sRad but close to the border with the stratum lacunosum moleculare (sLM). These interneurons also displayed clear axonal arborization primarily within the sLM and may represent some form of SCA or perforant-path-associated cell (Vida et al., 1998; Cope et al., 2002; Pawelzik et al., 2002). We did not observe any consistent morphological differences between either the GluK1 subunit-containing or GluK1 subunitnoncontaining population of interneurons in any dataset.

\section{ACET depresses disynaptic GABAergic synaptic transmission} onto CA1 pyramidal neurons

Finally, we examined the effect of blocking the KAR-mediated component of excitatory synaptic drive to interneurons on their GABAergic output to CA1 pyramidal neurons. IPSCs in pyramidal neurons were recorded in the presence of D-AP5 (50 $\mu 2)$ plus L-689,560 ( $5 \mu \mathrm{M})$ to block the NMDAR-mediated component of EPSCs; cells were held at $0 \mathrm{mV}$, the reversal potential for 
A
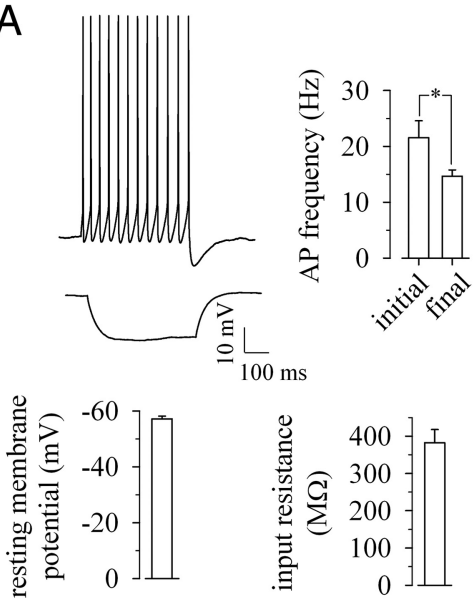

C

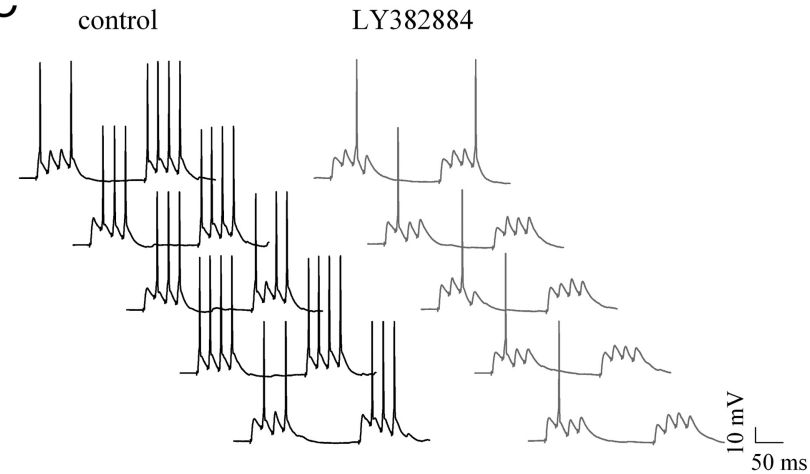

B

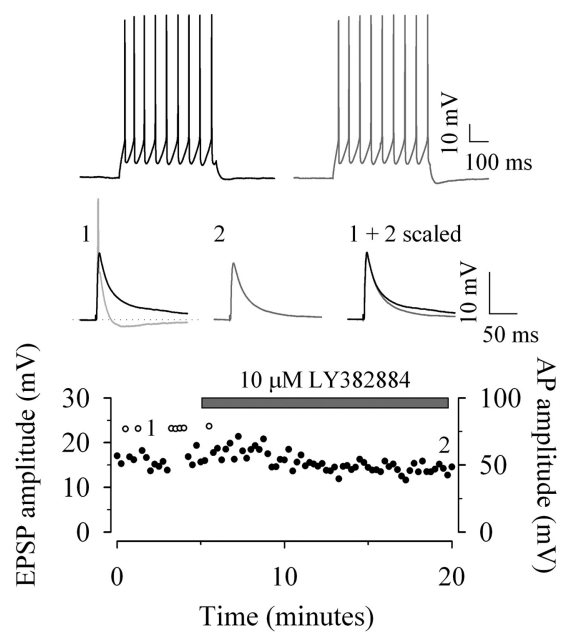

D
E

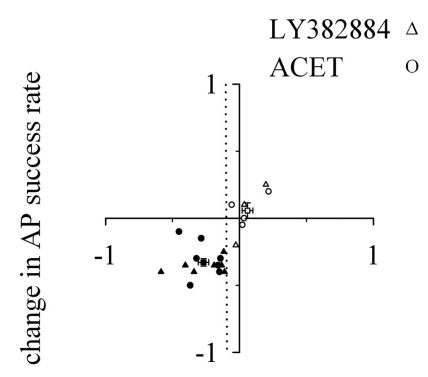

relative change in EPSP amplitude
F

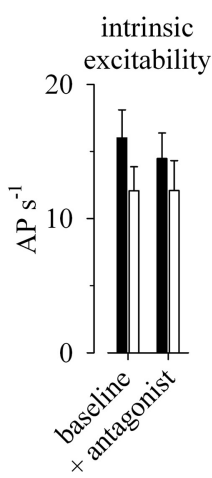

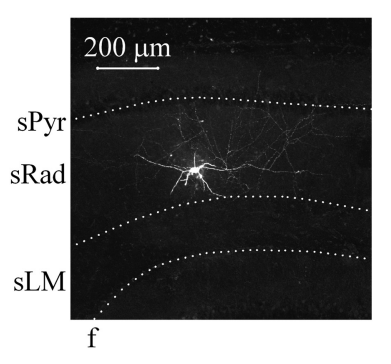

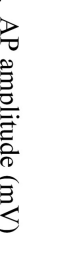



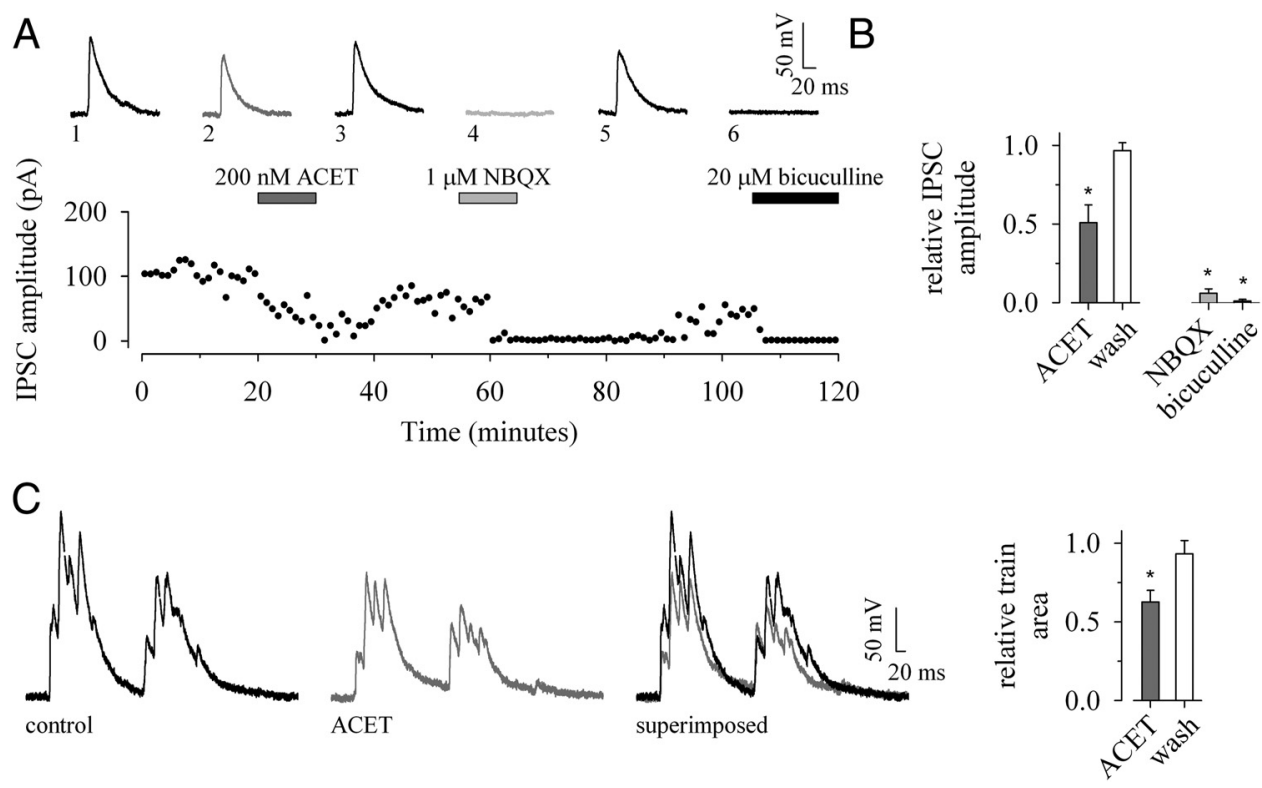

Figure 7. ACET depresses disynaptically evoked GABAergic synaptic transmission in CA1 pyramidal neurons. GABAergic responses are recorded in the presence of D-AP5 (50 $\mu \mathrm{M}) \mathrm{and} L-689,560$ $(5 \mu \mathrm{M})$ with neurons voltage-clamped at $0 \mathrm{mV}$. Bicuculline $(20 \mu \mathrm{M})$, applied at the end of each experiment, confirms events are $G A B A_{A} R$-mediated IPSCs. $\boldsymbol{A}-\boldsymbol{C}$, A single example $(\boldsymbol{A})$ and pooled data $(n=7)(B)$ to illustrate the effects of ACET (dark gray), NBQX (light gray), and bicuculline (black) on disynaptic IPSCs evoked at low frequency and $(\boldsymbol{C})$ charge transfer during TBS. The stimulating electrode was placed as far from the recording site as possible; the depression in the presence of NBQX confirms the disynaptic nature of the recorded events.

double exponential with a $\tau_{\mathrm{w}}$ of $28.1 \pm 2.4 \mathrm{~ms}(n=7)$. In contrast to its lack of effect on monosynaptic IPSCs, ACET strongly and reversibly attenuated disynaptic IPSC amplitude evoked at low frequency (by $49 \pm 11 \%$; $p<0.05$ ) and total charge transfer during TBS (as determined by the area under the train envelope) (by $37 \pm 7 \%$; $p<0.05)$ while having no effect on rise times $(+4 \pm$ $13 \% ; p>0.05$; data not shown) or weighted decay time constants $(-3 \pm 5 \% ; p>0.05$; data not shown). A subsequent application of the AMPAR antagonist NBQX reversibly blocked IPSC amplitude (by $96 \pm 3 \% ; p<0.05$ ), corroborating the disynaptic origin of the evoked IPSCs. Finally, bicuculline $(20 \mu \mathrm{M})$ abolished IPSC amplitude (by $99 \pm 3 \%$; $p<0.05$ ) confirming the $\mathrm{GABA}_{\mathrm{A}} \mathrm{R}-$ mediated nature of the events (Fig. $7 A-C$ ).

Together, these experiments indicate that physiologically activated KARs strongly regulate disynaptic GABAergic transmission onto CA1 pyramidal neurons during low-frequency and theta-burst activation of SCCP. Since KAR antagonism has no effect on monosynaptic IPSCs evoked by direct stimulation of interneuronal afferents, the attenuation of disynaptic IPSCs is consistent with a role for KAR-mediated excitatory synaptic transmission at SCCP-CA1 interneuron synapses.

\section{Discussion}

Although the presence of postsynaptic KARs in interneurons of the hippocampus is well documented (Cossart et al., 1998, 2002; Frerking et al., 1998; Goldin et al., 2007; Yang et al., 2007; Wondolowski and Frerking, 2009), physiological roles have only been described for interneurons exerting feedback GABAergic control within the CA1 circuitry (Goldin et al., 2007; Yang et al., 2007). We now show that KAR-mediated postsynaptic drive to feedforward interneurons plays a critical role in maintaining the threshold for induction of NMDAR-dependent LTP by shifting the dynamics of synaptic transmission at the SCCP-CA1 synapse in favor of GABAergic transmission. Thus, following attenuation of KAR activation, a previously subthreshold stimulus is sufficient to induce a long-term increase in synaptic efficacy. As such, this study provides the first evidence that the synaptic activation of
KARs in interneurons regulates the threshold for the induction of an NMDAR-dependent form of LTP.

\section{GluK1-containing KARs provide excitatory postsynaptic drive to sRad interneurons}

Pharmacological activation of KARs results in direct depolarization of interneurons, causing a large increase in spontaneous AP discharge and concomitant increase in spontaneous IPSC frequency at principal neurons (Cossart et al., 1998; Frerking et al., 1998). In agreement, by using two structurally unrelated KAR antagonists, namely ACET (Dolman et al., 2007; Dargan et al., 2009) and LY382884 (Bortolotto et al., 1999), we demonstrate that these receptors, most likely comprising or containing the GluK1 subunit, can participate in low-frequency glutamatergic synaptic transmission onto a subset of sRad interneurons and can provide significant synaptically mediated excitatory drive $(\sim 25 \%$ of overall charge transfer). In addition, neither antagonist had any effects on either passive membrane properties or intrinsic excitability. Therefore, the ability of this subpopulation to help maintain interneuronal firing must be accounted for by a KARmediated component of excitatory synaptic transmission. As a result, blocking this component of excitatory synaptic transmission greatly attenuates the output of interneurons to both lowfrequency evoked stimulation and also to natural-type firing patterns that typically occur at low frequency with short highfrequency bursts (i.e., TBS-like) commonly observed in vivo (Otto et al., 1991; O'Keefe and Recce, 1993).

At SCCP-interneuron synapses, KAR-mediated events with varying kinetics have been described. Although slower than EPSC $_{\text {AMPA }}$, both relatively fast (Cossart et al., 1998, 2002) and much slower events (Frerking et al., 1998; Wondolowski and Frerking, 2009) have been reported. Our data suggest that EPSC $_{\mathrm{KA}}$ regulating feedforward inhibition in area CA1 has relatively fast kinetics with similar rise times and decays that are only twofold slower when compared with those of EPSC $_{\mathrm{AMPA}}$ at these synapses. As a consequence, even excitatory synaptic drive and consequent AP generation following single-shock stimulation at 
low frequency to these interneurons can be affected by ACET, an observation consistent with its depressant effect on lowfrequency-evoked disynaptic GABAergic transmission.

\section{GluK1 subunit-containing KARs do not contribute to frequency facilitation of excitatory synaptic transmission to feedforward sRad interneurons}

In addition to a postsynaptic function to provide excitatory drive at a variety of synapses, KARs also function as autoreceptors located at presynaptic terminals to regulate the release of L-glutamate. Of these, one of the best characterized is the mf-CA3 synapse, where KAR activation augments evoked excitatory synaptic transmission during high-frequency trains (Lauri et al., 2001, 2003; Schmitz et al., 2001). Previous studies suggest a small subset of interneurons that contain the neuropeptide somatostatin and are located in area CA1 express unusually high facilitation due to the presence of a facilitatory presynaptic KAR autoreceptor (Sun et al., 2005; Sun and Dobrunz, 2006). The majority of interneurons recorded from in this study had a morphological appearance (Vida et al., 1998; Cope et al., 2002; Pawelzik et al., 2002; Ali, 2007) and basic electrophysiological characteristics (Pawelzik et al., 2002; Ali, 2007), such as spike frequency adaptation, consistent with those of SCAs. These cells are negative for somatostatin (but express cholecystokinin) (Cope et al., 2002; Pawelzik et al., 2002; Ali, 2007). As such, we did not observe any effect of ACET on overall facilitation during TBS protocols. However, we did observe SCCP-interneuron synapses that were capable of sustaining larger facilitation than at equivalent inputs to CA1 pyramidal neurons (Lauri et al., 2006) during the initial train of high-frequency stimulation of TBS. Intriguingly, a direct consequence is that, during TBS-like protocols, the greater facilitation at SCCP-interneuron synapses per se will cause a dynamic shift in excitation-inhibition balance in CA1 pyramidal neurons by favoring feedforward GABAergic drive. This, in turn, would tend to limit the induction of LTP to such protocols under control conditions.

As to the possible role of other types of interneurons in the present findings, the literature supports both expression of GluK1 subunits and function of KARs containing this subunit in interneurons with cell bodies in both stratum oriens and radiatum but not in principal cell layers (e.g., Cossart el al., 1998; Paternain et al., 2000). This would seem to rule out a role for those interneurons with cell bodies predominantly located in the stratum pyramidale. However, we cannot completely rule out the possible contribution of other interneurons (either feedforward or feedback) in the described phenomenon. For instance, feedback oriens-lacunosum moleculare interneurons also have GluK1 KARs capable of participating in synaptic transmission (Cossart et al., 1998; Oren et al., 2009) and, although ideally specialized to target perforant path inputs to CA1 arising from the entorhinal cortex, would be expected through electrotonic spread (e.g., Maccaferri et al., 2000) to exert influence on SCCP inputs to CA1 neurons.

\section{Theta-burst stimulation and LTP}

Successful induction of LTP in area CA1 depends on providing sufficient $\mathrm{Ca}^{2+}$ entry through synaptically activated NMDARs. Due to their slow time course and $\mathrm{Mg}^{2+}$ block at hyperpolarized potentials, the activation of NMDARs is critically dependent on levels of $\mathrm{GABA}_{\mathrm{A}} \mathrm{R}$-mediated feedforward inhibition (Bliss and Collingridge, 1993). This is particularly true for LTP induced by TBS-like protocols that reflect the physiologically relevant firing patterns observed in vivo from recordings of hippocampal place cells of behaving rats (Otto et al., 1991; O’Keefe and Recce, 1993).

Our data indicate that the synaptic activation of interneuronal KARs contributes significantly to feedforward GABAergic synaptic transmission and, consequently, to the regulation of LTP threshold in CA1 circuitry. By providing excitatory postsynaptic drive to interneurons, activation of KARs would help maintain all-or-none interneuron firing in response to afferent stimulation. Together with the relatively high levels of facilitation seen during TBS at this synapse compared with CA1 pyramidal neuron synapses, this will favor high levels of feedforward GABAergic transmission at SCCP-CA1 pyramidal synapses. If the KARmediated drive to interneurons is attenuated, the reduced excitatory drive to interneurons manifests as increased AMPAR activation at SCCP-CA1 pyramidal neurons during the TBS induction protocol. Consequently, a previously subthreshold stimulus now provides sufficient NMDAR activation to result in the induction of LTP.

The rhythmic firing of certain feedback CA1 interneurons is phase-locked to theta frequency by excitatory drive provided by GluK1 subunit-containing KARs (Goldin et al., 2007; Yang et al., 2007). It is interesting to speculate that a feedback mechanism could act in concert with the feedforward one described in this study. Thus, KARs may play a multifaceted role during this behaviorally relevant oscillation.

In summary, by contributing to high-frequency excitatory drive to interneurons, GluK1-containing KARs raise the threshold for the induction of theta-burst LTP by promoting a shift in the dynamics of synaptic transmission in favor of interneuronal output onto CA1 pyramidal neurons. This represents the first evidence for a physiological role for interneuronal KARs in gating an NMDAR-dependent form of long-term plasticity.

\section{References}

Ali AB (2007) Presynaptic inhibition of $\mathrm{GABA}_{\mathrm{A}}$ receptor-mediated unitary IPSPs by cannabinoid receptors at synapses between CCK-positive interneurons in rat hippocampus. J Neurophysiol 98:861-869. CrossRef Medline

Anderson WW, Collingridge GL (2007) Capabilities of the WinLTP data acquisition program extending beyond basic LTP experimental functions. J Neurosci Methods 162:346-356. CrossRef Medline

Bliss TV, Collingridge GL (1993) A synaptic model of memory: long-term potentiation in the hippocampus. Nature 361:31-39. CrossRef Medline

Bortolotto ZA, Clarke VR, Delany CM, Parry MC, Smolders I, Vignes M, Ho KH, Miu P, Brinton BT, Fantaske R, Ogden A, Gates M, Ornstein PL, Lodge D, Bleakman D, Collingridge GL (1999) Kainate receptors are involved in synaptic plasticity. Nature 402:297-301. CrossRef Medline

Buzsáki G (2005) Neuroscience: Similar is different in hippocampal networks. Science 309:568-569. CrossRef Medline

Clarke VR, Ballyk BA, Hoo KH, Mandelzys A, Pellizzari A, Bath CP, Thomas J, Sharpe EF, Davies CH, Ornstein PL, Schoepp DD, Kamboj RK, Collingridge GL, Lodge D, Bleakman D (1997) A hippocampal GluR5 kainate receptor regulating inhibitory synaptic transmission. Nature 389: 599-603. CrossRef Medline

Cope DW, Maccaferri G, Márton LF, Roberts JD, Cobden PM, Somogyi P (2002) Cholecystokinin-immunopositive basket and schaffer collateralassociated interneurones target different domains of pyramidal cells in the CA1 area of the rat hippocampus. Neuroscience 109:63-80. CrossRef Medline

Cossart R, Esclapez M, Hirsch JC, Bernard C, Ben-Ari Y (1998) GluR5 kainate receptor activation in interneurons increases tonic inhibition of pyramidal cells. Nat Neurosci 1:470-478. CrossRef Medline

Cossart R, Tyzio R, Dinocourt C, Esclapez M, Hirsch JC, Ben-Ari Y, Bernard C (2001) Presynaptic kainate receptors that enhance the release of GABA on CA1 hippocampal interneurons. Neuron 29:497-508. CrossRef Medline

Cossart R, Epsztein J, Tyzio R, Becq H, Hirsch J, Ben-Ari Y, Crépel V (2002) 
Quantal release of glutamate generates pure kainate and mixed AMPA/ kainate EPSCs in hippocampal neurons. Neuron 35:147-159. CrossRef Medline

Dargan SL, Clarke VR, Alushin GM, Sherwood JL, Nisticò R, Bortolotto ZA, Ogden AM, Bleakman D, Doherty AJ, Lodge D, Mayer ML, Fitzjohn SM, Jane DE, Collingridge GL (2009) ACET is a highly potent and specific kainate receptor antagonist: characterisation and effects on hippocampal mossy fibre function. Neuropharmacology 56:121-130. CrossRef Medline

Davies CH, Starkey SJ, Pozza MF, Collingridge GL (1991) GABA autoreceptors regulate the induction of LTP. Nature 349:609-611. CrossRef Medline

Diamond DM, Dunwiddie TV, Rose GM (1988) Characteristics of hippocampal primed burst potentiation in vitro and in the awake rat. J Neurosci 8:4079-4088. Medline

Dolman NP, More JC, Alt A, Knauss JL, Pentikäinen OT, Glasser CR, Bleakman D, Mayer ML, Collingridge GL, Jane DE (2007) Synthesis and pharmacological characterization of N3-substituted willardiine derivatives: role of the substituent at the 5-position of the uracil ring in the development of highly potent and selective GLUK5 kainate receptor antagonists. J Med Chem 50:1558-1570. CrossRef Medline

Frerking M, Malenka RC, Nicoll RA (1998) Synaptic activation of kainate receptors on hippocampal interneurons. Nat Neurosci 1:479-486. CrossRef Medline

Goldin M, Epsztein J, Jorquera I, Represa A, Ben-Ari Y, Crépel V, Cossart R (2007) Synaptic kainate receptors tune oriens-lacunosum moleculare interneurons to operate at theta frequency. J Neurosci 27:9560-9572. CrossRef Medline

Gulyás AI, Tóth K, McBain CJ, Freund TF (1998) Stratum radiatum giant cells: a type of principal cell in the rat hippocampus. Eur J Neurosci 10:3813-3822. CrossRef Medline

Huerta PT, Lisman JE (1993) Heightened synaptic plasticity of hippocampal CA1 neurons during a cholinergically induced rhythmic state. Nature 364:723-725. CrossRef Medline

Huxter JR, Zinyuk LE, Roloff EL, Clarke VR, Dolman NP, More JC, Jane DE, Collingridge GL, Muller RU (2007) Inhibition of kainate receptors reduces the frequency of hippocampal theta oscillations. J Neurosci 27: 2212-2223. CrossRef Medline

Hyman JM, Wyble BP, Goyal V, Rossi CA, Hasselmo ME (2003) Stimulation in hippocampal region CA1 in behaving rats yields long-term potentiation when delivered to the peak of theta and long-term depression when delivered to the trough. J Neurosci 23:11725-11731. Medline

Larson J, Wong D, Lynch G (1986) Patterned stimulation at the theta frequency is optimal for the induction of hippocampal long-term potentiation. Brain Res 368:347-350. CrossRef Medline

Lauri SE, Bortolotto ZA, Bleakman D, Ornstein PL, Lodge D, Isaac JT, Collingridge GL (2001) A critical role of a facilitatory presynaptic kainate receptor in mossy fiber LTP. Neuron 32:697-709. CrossRef Medline

Lauri SE, Bortolotto ZA, Nistico R, Bleakman D, Ornstein PL, Lodge D, Isaac JT, Collingridge GL (2003) A role for $\mathrm{Ca}^{2+}$ stores in kainate receptordependent synaptic facilitation and LTP at mossy fiber synapses in the hippocampus. Neuron 39:327-341. CrossRef Medline

Lauri SE, Vesikansa A, Segerstråle M, Collingridge GL, Isaac JT, Taira T (2006) Functional maturation of CA1 synapses involves activitydependent loss of tonic kainate receptor-mediated inhibition of glutamate release. Neuron 50:415-429. CrossRef Medline

Maccaferri G, Roberts JD, Szucs P, Cottingham CA, Somogyi P (2000) Cell surface domain specific postsynaptic currents evoked by identified GABAergic neurons in rat hippocampus in vitro. J Physiol 524:91-116. CrossRef Medline

Mann EO, Paulsen O (2007) Role of GABAergic inhibition in hippocampal network oscillations. Trends Neurosci 30:343-349. CrossRef Medline

Min MY, Melyan Z, Kullmann DM (1999) Synaptically released glutamate reduces gamma-aminobutyric acid (GABA)ergic inhibition in the hippocampus via kainate receptors. Proc Natl Acad Sci U S A 96:9932-9937. CrossRef Medline

O'Keefe J, Recce ML (1993) Phase relationship between hippocampal place units and the EEG theta rhythm. Hippocampus 3:317-330. CrossRef Medline

Oren I, Nissen W, Kullmann DM, Somogyi P, Lamsa KP (2009) Role of ionotropic glutamate receptors in long-term potentiation in rat hippocampal CA1 oriens-lacunosum moleculare interneurons. J Neurosci 29:939-950. CrossRef Medline

Otto T, Eichenbaum H, Wiener SI, Wible CG (1991) Learning-related patterns of CA1 spike trains parallel stimulation parameters optimal for inducing hippocampal long-term potentiation. Hippocampus 1:181192. CrossRef Medline

Paternain AV, Herrera MT, Nieto MA, Lerma J (2000) GluR5 and GluR6 kainate receptor subunits coexist in hippocampal neurons and coassemble to form functional receptors. J Neurosci 20:196-205. Medline

Pavlides C, Greenstein YJ, Grudman M, Winson J (1988) Long-term potentiation in the dentate gyrus is induced preferentially on the positive phase of theta-rhythm. Brain Res 439:383-387. CrossRef Medline

Pawelzik H, Hughes DI, Thomson AM (2002) Physiological and morphological diversity of immunocytochemically defined parvalbumin and cholecystokinin-positive interneurones in CA1 of the adult rat hippocampus. J Comp Neurol 443:346-367. CrossRef Medline

Perrais D, Pinheiro PS, Jane DE, Mulle C (2009) Antagonism of recombinant and native GluK3-containing kainate receptors. Neuropharmacology 56:131-140. CrossRef Medline

Pinheiro PS, Lanore F, Veran J, Artinian J, Blanchet C, Crépel V, Perrais D, Mulle C (2012) Selective block of postsynaptic kainate receptors reveals their function at hippocampal mossy fiber synapses. Cereb Cortex. Advance online publication. Retrieved Nov. 8, 2012. doi:10.1093/cercor/ bhs022. CrossRef Medline

Rodríguez-Moreno A, Herreras O, Lerma J (1997) Kainate receptors presynaptically downregulate GABAergic inhibition in the rat hippocampus. Neuron 19:893-901. CrossRef Medline

Schmitz D, Mellor J, Nicoll RA (2001) Presynaptic kainate receptor mediation of frequency facilitation at hippocampal mossy fiber synapses. Science 291:1972-1976. CrossRef Medline

Somogyi P, Klausberger T (2005) Defined types of cortical interneurone structure space and spike timing in the hippocampus. J Physiol 562:9-26. Medline

Stäubli U, Scafidi J, Chun D (1999) $\mathrm{GABA}_{\mathrm{B}}$ receptor antagonism: facilitatory effects on memory parallel those on LTP induced by TBS but not HFS. J Neurosci 19:4609-4615. Medline

Sun HY, Dobrunz LE (2006) Presynaptic kainate receptor activation is a novel mechanism for target cell-specific short-term facilitation at Schaffer collateral synapses. J Neurosci 26:10796-10807. CrossRef Medline

Sun HY, Lyons SA, Dobrunz LE (2005) Mechanisms of target-cell specific short-term plasticity at Schaffer collateral synapses onto interneurones versus pyramidal cells in juvenile rats. J Physiol 568:815-840. CrossRef Medline

Vanderwolf CH (1969) Hippocampal electrical activity and voluntary movement in the rat. Electroencephalogr Clin Neurophysiol 26:407-418. CrossRef Medline

Vida I, Halasy K, Szinyei C, Somogyi P, Buhl EH (1998) Unitary IPSPs evoked by interneurons at the stratum radiatum-stratum lacunosummoleculare border in the CA1 area of the rat hippocampus in vitro. J Physiol 506:755-773. CrossRef Medline

Wondolowski J, Frerking M (2009) Subunit-dependent postsynaptic expression of kainate receptors on hippocampal interneurons in area CA1. J Neurosci 29:563-574. CrossRef Medline

Yang EJ, Harris AZ, Pettit DL (2007) Synaptic kainate currents reset interneuron firing phase. J Physiol 578:259-273. Medline 